\title{
Processes Governing Water Vapor Isotope Composition in the Indo-Pacific Region: Convection and Water Vapor Transport ${ }^{\circ}$
}

\author{
ZHONGYIN CAI \\ Key Laboratory of Tibetan Environment Changes and Land Surface Processes, Institute of Tibetan Plateau Research, \\ Chinese Academy of Sciences, and University of Chinese Academy of Sciences, Beijing, China
}

\section{LIDE TIAN}

Key Laboratory of Tibetan Environment Changes and Land Surface Processes, Institute of Tibetan Plateau Research, Chinese Academy of Sciences, and Chinese Academy of Sciences Center for Excellence in Tibetan Plateau Earth Sciences, Beijing, China

(Manuscript received 11 April 2016, in final form 23 August 2016)

\begin{abstract}
In an effort to understand the mechanisms controlling water vapor isotope composition in the Indo-Pacific region, encompassing southeastern Asia, this study investigates the spatial and interannual patterns in summer [June-September (JJAS)] water vapor isotopologues retrieved from the Tropospheric Emission Spectrometer (TES), especially those patterns associated with convection and water vapor transport. Both precipitation and water vapor isotope values exhibit a $\mathrm{V}$-shaped longitudinal pattern in their spatial variations, reflecting the gradual rainout and increase in convective intensity along water vapor transport routes. On the temporal scale, compared with the 2006-10 JJAS mean conditions, TES water vapor $\delta \mathrm{D}$ over the eastern Indian Ocean and southeastern Asia (R_W $\left.120 ; 10^{\circ} \mathrm{S}-30^{\circ} \mathrm{N}, 80^{\circ}-120^{\circ} \mathrm{E}\right)$ is higher in the $2009 \mathrm{JJAS} \mathrm{El}$ Niño event when convective activity is reduced and lower in the 2010 JJAS La Niña event when convective activity is enhanced. This is consistent with the direct response of water vapor $\delta \mathrm{D}$ to deep convection. In contrast, TES water vapor $\delta \mathrm{D}$ over the western Pacific (R_WP $\left.10^{\circ} \mathrm{S}-30^{\circ} \mathrm{N}, 120^{\circ}-140^{\circ} \mathrm{E}\right)$ is higher in the La Niña year than in the El Niño year, although convective activity in R_WP varies in the same manner as in R_W120. A comparison of water vapor $\delta \mathrm{D}$ values with convection and water vapor transport suggests that the westward transport of water vapor-isotopic anomalies and changes in the flux of water vapor transported from the central to the western Pacific lead to such an opposite response in the R_WP. These findings help interpret what causes the interannual variations recorded by Indo-Pacific water isotopologues.
\end{abstract}

\section{Introduction}

El Niño-Southern Oscillation (ENSO) is the dominant source of tropical interannual variability and exerts a global impact on both climate and environment (e.g., Krishnamurti et al. 2013). The rainfall regimes and atmospheric circulation in the Indo-Pacific region, encompassing southeastern Asia, home to over $60 \%$ of humanity, are

Supplemental information related to this paper is available at the Journals Online website: http://dx.doi.org/10.1175/ JCLI-D-16-0297.s1.

Corresponding author address: Lide Tian, Key Laboratory of Tibetan Environment Changes and Land Surface Processes, Institute of Tibetan Plateau Research, Chinese Academy of Sciences, Building 3, Courtyard 16, Lin Cui Road, Chaoyang District, Beijing 100101, China.

E-mail: ldt@itpcas.ac.cn influenced by ENSO mainly through the changes in the Walker circulation (e.g., Ju and Slingo 1995; Krishnamurthy and Krishnamurthy 2014; Trenberth 1997). In general, the warm phase (El Niño) of ENSO triggers the weakening of the Walker circulation and drier conditions in the western Pacific and South Asia. In contrast, the cold phase (La Niña) is marked by stronger rainfall in these regions. In addition, water vapor from the Indian Ocean is the major source of summer [June-September (JJAS)] monsoonal rainfall, which dominates the precipitation pattern in southeastern Asia (e.g., An et al. 2015; Ding and Chan 2005; Wang and LinHo 2002), while water vapor from the western Pacific partially contributes to the precipitation in East Asia (e.g., Nan et al. 2014; Sengupta and Sarkar 2006; Tan 2014; Tian et al. 2001; van der Ent and Savenije 2013; Yao et al. 2013). It is therefore important to study how ENSO influences the summer climate, such as moisture dynamics and convection, in the Indo-Pacific region. 
Water isotope signals $\left(\delta \mathrm{D}\right.$ and $\left.\delta^{18} \mathrm{O}\right)$ are important tools in the study of present and past climate and hydrological cycle, since isotopic fractionation during water phase changes leaves a distinct imprint on the isotopic composition of precipitation and water vapor (e.g., Lee et al. 2011; Noone 2012; Thompson et al. 2000; Yao et al. 2013). For instance, water isotope signals have been successfully used to delineate summer monsoon onset processes (Srivastava et al. 2015; Yang et al. 2012; Yu et al. 2016), the northern extent of the Indian summer monsoon (ISM) on the Tibetan Plateau (Tian et al. 2001, 2007), and the various contributions made by different water vapor sources (Sengupta and Sarkar 2006). In addition, several previous studies from stations or areas in the Indo-Pacific region have revealed that there is a connection between ENSO and isotopic composition of precipitation from this region (Cai and Tian 2016; Conroy et al. 2013; Ichiyanagi and Yamanaka 2005; Ishizaki et al. 2012; Tan 2014). Generally, precipitation isotope values in the central part of this region (e.g., southeastern Asia and the western Pacific) are positively correlated with the ENSO signal, with higher isotope values during the ENSO warm phases and lower isotope values during the ENSO cold phases. However, the causes of this connection have been explained in different ways, such as precipitation amount (Ichiyanagi and Yamanaka 2005), distillation along transport pathway (Ishizaki et al. 2012), condensation height driven by regional convective reorganization (Cai and Tian 2016), or relative contributions made by water vapor transported from different source regions (Tan 2014).

When interpreting climatic controls on tropical or monsoonal water isotopologues, most studies invoke the "amount effect," a negative correlation between precipitation $\delta^{18} \mathrm{O}$ and precipitation amount (Dansgaard 1964). Several processes have been shown to contribute to the amount effect, including convective or mesoscale downdrafts and rain reevaporation (Kurita 2013; Lee and Fung 2008; Risi et al. 2008a,b), the relative contribution of largescale convergence and of surface evaporation to the water budget (Lee et al. 2007; Moore et al. 2014), or the altitude of cloud condensation (Cai and Tian 2016; Scholl et al. 2009).

However, precipitation is the end product of water vapor movement and phase changes, making the interpretation of precipitation isotopic signal challenging and sometime equivocal. Fortunately, the recently available satellite observations of water vapor isotopologues ( $\mathrm{HDO}$ and $\mathrm{H}_{2} \mathrm{O}$ ) have shown their potential and advantage in characterizing atmospheric processes governing the isotopic composition of water vapor, as well as precipitation (e.g., Lee et al. 2012, 2015; Sutanto et al. 2015). Most of them emphasize the role of convection in determining the isotopic composition of water vapor, and especially its temporal variation. For instance, Lee et al.
(2015) examined how water vapor isotopologues responded to the October-December 2006 El Niño through changes in convection. Sutanto et al. (2015) found an inverse response between near-surface and midtroposphere water vapor isotopologues to ENSO, and concluded that strong convection isotopically depletes near-surface water vapor, but that enhanced vertical transport of isotopically enriched water vapor from the surface during strong convection increases the water vapor isotope values in the midtroposphere. However, horizontal water vapor transport also plays an important role in determining the spatial and temporal variations in water vapor isotope composition (e.g., Okazaki et al. 2015; Yoshimura et al. 2003). (Note: if not specified, the term "transport" used in this study means horizontal water vapor transport and does not include the vertical path, which is part of the convection processes.) With this in mind, might it be possible to use water vapor isotopologue data to support or discard the hypothesis that changes in the relative contributions made by water vapor transported from different source regions are responsible for the relations between precipitation $\delta^{18} \mathrm{O}$ and ENSO in the monsoonal regions of China (Nan et al. 2014; Tan 2014)? As the influence of water vapor transport on the temporal variations in the isotopic composition of water vapor is determined by both transport intensity and the spatial isotope gradient [e.g., Eq. (5) in Okazaki et al. (2015)], understanding the characteristics of the spatial variations inherent in the isotopic composition of water vapor is needed before investigating the interannual variations.

With this premise as a background, we aim at characterizing the spatial and temporal patterns evident in IndoPacific summer water vapor isotopologues, and any possible underlying mechanisms, especially the processes governing the interannual patterns in the water vapor isotopologues. In this study, we first investigated the spatial patterns of precipitation $\delta^{18} \mathrm{O}$ and satellite water vapor $\delta \mathrm{D}\left(\delta \mathrm{D}_{v}\right)$ over the Indo-Pacific region. Then, we analyzed the interannual variations in water vapor isotope composition in the central part of the Indo-Pacific region $\left(10^{\circ} \mathrm{S}-30^{\circ} \mathrm{N}, 80^{\circ}-140^{\circ} \mathrm{E}\right)$. To unveil the underlying mechanism of these spatial and temporal patterns, we further investigated their associations with convection and water vapor transport.

\section{Data and methods}

\section{a. Isotope data}

The Tropospheric Emission Spectrometer (TES) onboard Aura allows $\mathrm{HDO}$ and $\mathrm{H}_{2} \mathrm{O}$ retrievals in a spectral range between 650 and $3050 \mathrm{~cm}^{-1}$ having a footprint of $5.3 \mathrm{~km} \times 8.4 \mathrm{~km}$ (e.g., Worden et al. 2006 , 2011). Water vapor isotopologue retrievals for individual 
measurements have a precision about $10 \%-15 \%$, but when calculating zonal averages the precision is $1 \%-2 \%$ (Risi et al. 2012). The TES water vapor isotopologue retrieval sensitivity is the highest in the tropics and lower at high latitudes because of its dependence on specific humidity and temperature (Worden et al. 2006). Cloud covers may affect the vertical resolution (Worden et al. 2006) and thus lead the retrievals to underestimate the difference between boundary layer cloud condition and clear-sky condition (Lee et al. 2011). However, this instrument sensitivity does not impact the variability; for example, Sutanto et al. (2015) found similar results before and after the cloud filter.

Only the TES water vapor isotopologue retrievals for 2006-10 cover the JJAS period for every year. We therefore used the TES Lite product (version 6) for 2006-10, which aggregates monthly retrieval results and applies known corrections through validations (Worden et al. 2012). The TES retrievals are available online (http://tesweb.jpl.nasa.gov/data/). Compared with early TES data releases, the recent TES level-2 version-5 dataset demonstrates an improved performance, with comparably high sensitivity across a wider altitude range between 925 and $350 \mathrm{hPa}$ (Worden et al. 2012). Before processing the data, we filtered the TES data using the following criterion: a degree of freedom for signals $>0.5$ when species retrieval quality is 1 . After the filtering procedures, one dataset was generated for each year's JJAS period. The TES water vapor isotopologue retrievals have 17 pressure levels. In this study, analyses are based on total column $\delta \mathrm{D}_{v}$ (i.e., the $\mathrm{H}_{2} \mathrm{O}$ concentration weighted mean $\delta \mathrm{D}_{v}$ from surface to the top of the atmosphere). More specifically, total column $\delta \mathrm{D}_{v}$ is calculated as $\delta \mathrm{D}_{v}=\sum_{i=1}^{17}\left(\delta \mathrm{D}_{i} q_{i} \Delta P_{i}\right) / \sum_{i=1}^{17}\left(q_{i} \Delta P_{i}\right)$, where $\delta \mathrm{D}_{i}$ is the water vapor-isotopic composition, $q_{i}$ is the $\mathrm{H}_{2} \mathrm{O}$ volume mixing ratio for each pressure level, and $\Delta P_{i}$ is the pressure thickness of each layer.

To compare the spatial distributions of precipitation and water vapor isotopes, monthly precipitation $\delta^{18} \mathrm{O}$ data were obtained from the Global Network of Isotopes in Precipitation (GNIP) database that is available online (https://nucleus.iaea.org/wiser). These data are from stations located within the $0^{\circ}-30^{\circ} \mathrm{N}, 60^{\circ} \mathrm{E}-150^{\circ} \mathrm{W}$ sector. Besides using GNIP data, we have collected event-based precipitation samples at Lhasa, on the southern Tibetan Plateau, since 1993 [see the review article Yao et al. (2013) for details about the Tibetan Network for Isotopes in Precipitation (TNIP) and the relevant sampling and measuring procedures]. From the monthly and event-based data, long-term mean JJAS seasonal precipitation $\delta^{18} \mathrm{O}$ values were taken as representing the precipitation weighted mean $\delta^{18} \mathrm{O}$. To get the long-term averaged JJAS seasonal precipitation $\delta^{18} \mathrm{O}$ values, we first calculated the long-term mean monthly values. Then the JJAS seasonal precipitation $\delta^{18} \mathrm{O}$ values are the precipitation amount weighted mean $\delta^{18} \mathrm{O}$.

\section{b. Climate data}

The National Oceanic and Atmospheric Administration (NOAA)/Climate Prediction Center (CPC) provides the current and historical ENSO assessments and the oceanic Niño index [ONI; sea surface temperature (SST) anomalies from 1981 to 2010 in the Niño-3.4 region $\left.\left(5^{\circ} \mathrm{S}-5^{\circ} \mathrm{N}, 170^{\circ} \mathrm{E}-120^{\circ} \mathrm{W}\right)\right]$ online (http://www.cpc.noaa.gov/ products/analysis_monitoring/ensostuff/ensoyears2011. shtml). Global Precipitation Climatology Project (GPCP) monthly precipitation data (Adler et al. 2003) and outgoing longwave radiation (OLR) data (Liebmann and Smith 1996) with a $2.5^{\circ} \times 2.5^{\circ}$ resolution were used to measure precipitation and convection. Both GPCP and OLR data are available online (http://www.esrl.noaa.gov/ psd/data/gridded/data.gpcp.html and http://www.esrl. noaa.gov/psd/data/gridded/data.interp_OLR.html).

Additionally, satellite cloud products from the International Satellite Cloud Climatology Project (ISCCP; cloud-top pressure in the D2 dataset) with a $2.5^{\circ} \times 2.5^{\circ}$ resolution (Rossow and Schiffer 1999) were used to reconstruct cloud-top height and convection. Further, ERA-Interim data at a resolution of $2.5^{\circ} \times 2.5^{\circ}$ and at 37 pressure levels (Dee et al. 2011) were used to characterize atmospheric circulation and water vapor transport. As vertical velocity at the $500-\mathrm{hPa}$ level $\omega$ is an indicator of surface convergence strength (Feng et al. 2009), we also used the $\omega$ values included in the ERAInterim data. To quantify land and sea surface evaporation, we used ERA-Interim/Land data (Balsamo et al. 2015). The ISCCP D2 data are available online (http:// isccp.giss.nasa.gov/products/onlineData.html). Both the ERA-Interim and ERA-Interim/Land data are also available online (http://apps.ecmwf.int/datasets/).

\section{Spatial and interannual patterns in Indo-Pacific water vapor isotopologues}

\section{a. Spatial patterns in precipitation and water vapor isotopologues}

There are two dominant features in the spatial distribution of JJAS seasonal precipitation $\delta^{18} \mathrm{O}$ for the Indo-Pacific region: a gradual decrease in $\delta^{18} \mathrm{O}$ with increasing altitude and a zonal $\mathrm{V}$-shaped pattern in its longitudinal variation (Fig. 1). The JJAS seasonal precipitation $\delta^{18} \mathrm{O}$ ranges from $-1.1 \%$ to $-17.0 \%$, with a lapse rate of $0.23 \%(100 \mathrm{~m})^{-1}$ (Fig. S1 in the supplemental material). To separate the vertical and horizontal components of spatial variations in $\delta^{18} \mathrm{O}$, we removed the altitude effect by adding the product of the calculated 

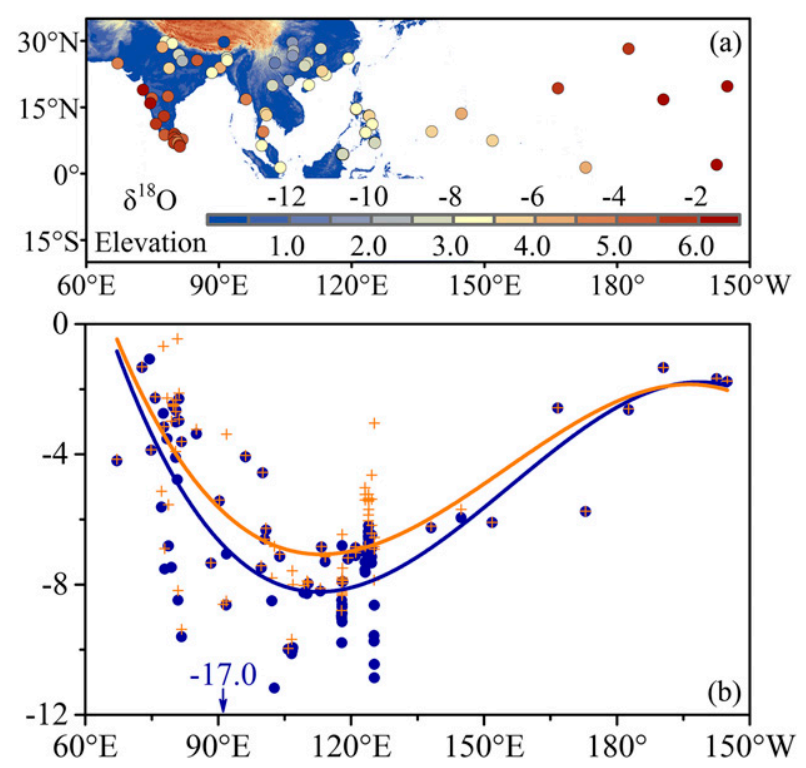

FIG. 1. (a) Spatial distribution of JJAS seasonal precipitation $\delta^{18} \mathrm{O}$ (filled circles; \%o ) and terrain height (shading; $10^{3} \mathrm{~m}$ ) in the Indo-Pacific region. (b) Longitudinal variations in precipitation $\delta^{18} \mathrm{O}$ (blue dots indicate the raw data; the blue arrow and number indicate the situation at Lhasa; and orange crosses indicate values after the removal of the altitude effect) and the longitudinal trend in $\delta^{18} \mathrm{O}$ [solid lines represent the third-order polynomial fit lines for raw (blue) and adjusted data (orange)].

lapse rate $\left[0.23 \%(100 \mathrm{~m})^{-1}\right]$ and the altitude of each station. Results show that even when the altitude effect has been removed, the longitudinal variation in precipitation $\delta^{18} \mathrm{O}$ still shows a clear V-shaped pattern (Fig. 1b).

The spatial distribution of total column JJAS TES $\delta \mathrm{D}_{v}$ values (Fig. 2a) resembles that of JJAS precipitation $\delta^{18} \mathrm{O}$ (Fig. 1); that is, the lowest values are over the Tibetan Plateau (TP) and there is a V-shaped pattern in its longitudinal variation. The TP has altitudes that reach into the midtroposphere, so the isotopic signature there mainly reflects water vapor isotope composition in the mid-toupper troposphere, which by its very nature is much more isotopically depleted than in the lower troposphere. The similar spatial patterns in precipitation $\delta^{18} \mathrm{O}$ and TES $\delta \mathrm{D}_{v}$ indicate the strong physical linkages between them.

\section{b. Interannual patterns}

To explore the response of atmospheric water vapor $\delta \mathrm{D}_{v}$ values to $\mathrm{ENSO}$, we employed a case study for an $\mathrm{El}$ Niño event in 2009 and a La Niña event in 2010. Conditions across the equatorial Pacific Ocean transitioned from ENSO-neutral to El Niño conditions from June 2009, and the El Niño dissipated during May 2010. But La Niña conditions developed from June 2010 and went back to ENSO-neutral conditions during May 2011. The seasonal JJAS Niño-3.4 SST anomaly (ONI) was $0.54^{\circ} \mathrm{C}$ in 2009 and $-0.95^{\circ} \mathrm{C}$ in 2010 . This event in 2009 is representative of a typical El Niño case and 2010 is a typical La Niña case (section $4 c$ ).

Figures $2 \mathrm{~b}$ and $2 \mathrm{c}$ show the TES $\delta \mathrm{D}_{v}$ anomalies during the 2009 JJAS El Niño event and the 2010 JJAS La Niña event, relative to 2006-10 JJAS mean. The results indicate that, over the central part of the Indo-Pacific region, a boundary roughly located at $120^{\circ} \mathrm{E}$ separates the positive and negative $\delta \mathrm{D}_{v}-\mathrm{ENSO}$ responses into west and east. Thus, two regions can be delineated for further investigation: the eastern Indian Ocean and southeastern Asia $\left(\mathrm{R}_{-} \mathrm{W} 120 ; 10^{\circ} \mathrm{S}-30^{\circ} \mathrm{N}, 80^{\circ}-120^{\circ} \mathrm{E}\right)$ and (a) ALL mean

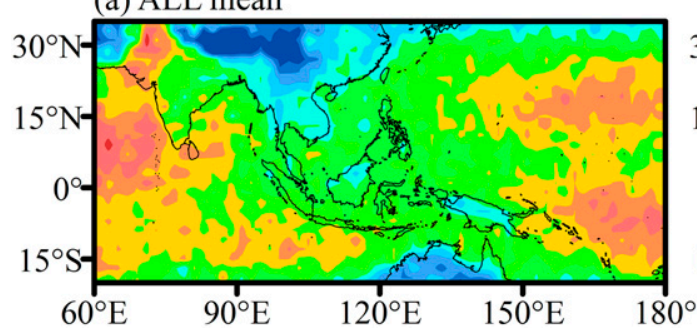

(c) 2010 JJAS anomaly

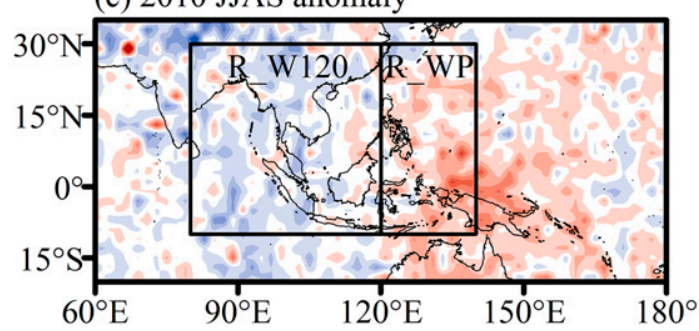

(b) 2009 JJAS anomaly

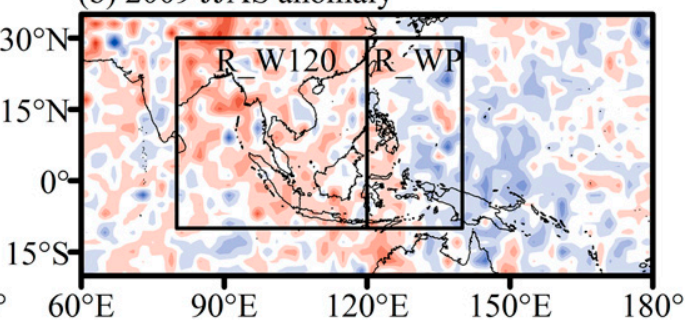

Scale for (a)

\begin{tabular}{cccccc}
\hline-160 & -140 & -120 & -100 & -80 & -60
\end{tabular}

Scale for (b) and (c)

$-55-45-35-25-15 \quad-5 \quad 5 \quad 15253545 \quad 55$

FIG. 2. JJAS seasonal averages of total column TES water vapor isotopologues $\left(\delta \mathrm{D}_{v} ; \%\right.$ oo $)$ for (a) the $2006-10$ (ALL) mean, (b) the 2009 anomaly, and (c) the 2010 anomaly. Rectangles in (b) and (c) denote the location of the two regions: R_W120 and R_WP. Note that any anomalies are relative to the 2006-10 JJAS mean. 


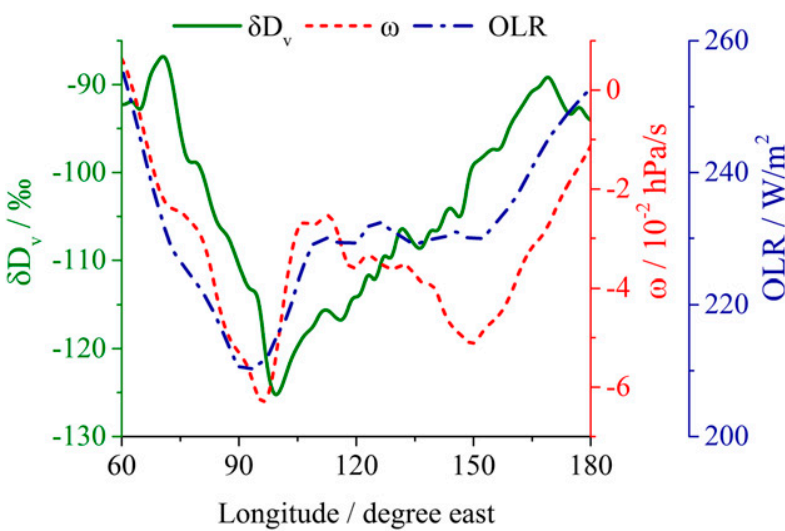

FIG. 3. Longitudinal variations in TES $\delta \mathrm{D}_{v}$, vertical velocity at $500 \mathrm{hPa}$ (with negative values indicating upward air motion), and OLR for the latitude band $10^{\circ} \mathrm{S}-30^{\circ} \mathrm{N}$ from 2006 to 2010 .

the western Pacific (R_WP; $10^{\circ} \mathrm{S}-30^{\circ} \mathrm{N}, 120^{\circ}-140^{\circ} \mathrm{E}$ ). TES $\delta \mathrm{D}_{v}$ values over the R_W120 are higher in JJAS 2009, but lower in JJAS 2010 (positive response), in agreement with precipitation isotope studies that precipitation $\delta^{18} \mathrm{O}$ in this region is positively correlated with ENSO signal (e.g., Cai and Tian 2016; Ishizaki et al. 2012). However, over the western-to-central Pacific (roughly east of $120^{\circ} \mathrm{E}$, including the R_WP), negative TES $\delta \mathrm{D}_{v}$ anomalies dominate in the El Niño year and positive TES $\delta \mathrm{D}_{v}$ anomalies dominate in the La Niña year (negative response), in contrast to its westernmost sector. Over the central Pacific, this result is due to the opposite response of convection to ENSO events. The response of TES $\delta \mathrm{D}_{v}$ over the R_W120 and the central Pacific correlates with previous explanations of changes in the strength of convection (Lee et al. 2015; Sutanto et al. 2015). However, the opposite response of TES $\delta \mathrm{D}_{v}$ values noted over the R_WP has not yet been reported upon, and so any underlying mechanisms remain unexplored.

\section{Atmospheric controls on these spatial and temporal patterns}

\section{a. Spatial patterns}

The longitudinal variation in TES $\delta \mathrm{D}_{v}$ also shows a clear V-shaped pattern like precipitation $\delta^{18} \mathrm{O}$ (Fig. 3). In addition, the longitudinal patterns in TES $\delta \mathrm{D}_{v}$ and precipitation $\delta^{18} \mathrm{O}$ values partially resemble the longitudinal patterns in convection and upward air motion intensity (Figs. 1b and 3). Such a resemblance would indicate that a longitudinal pattern in convection intensity is one factor controlling the isotopic composition of water vapor and precipitation: locations experiencing stronger convection have lower isotopic values. A comparison between spatial patterns in the water isotopologues (Figs. 1a and 2a) and precipitation and

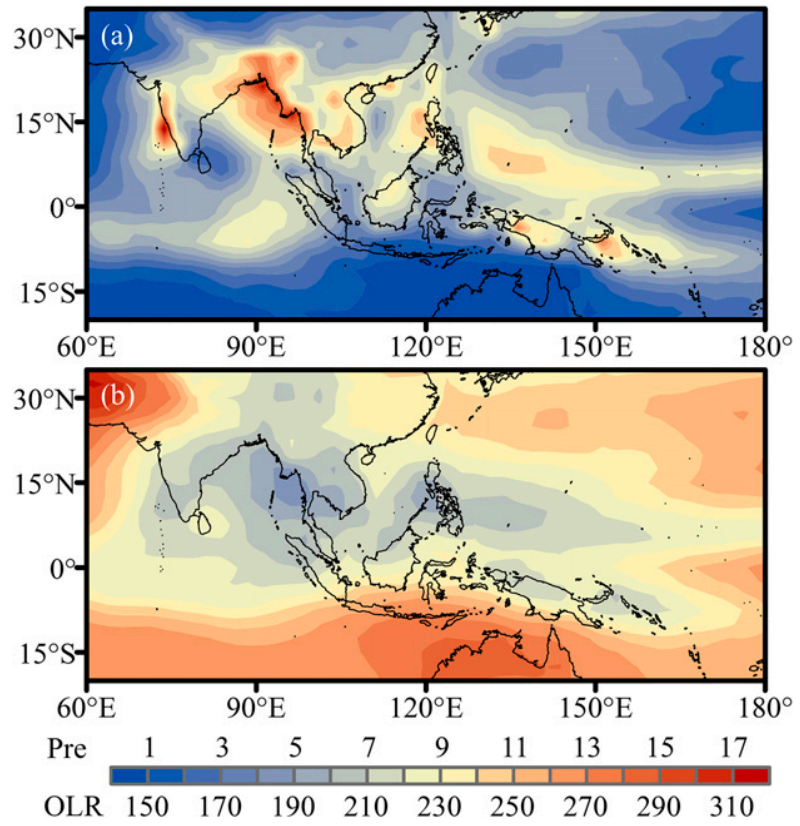

FIG. 4. JJAS seasonal averages of (a) GPCP precipitation $\left(\mathrm{mm} \mathrm{day}^{-1}\right)$ and (b) NOAA OLR $\left(\mathrm{W} \mathrm{m}^{-2}\right)$ for the 2006-10 mean.

convection intensity (Fig. 4) further confirms that spatial variations in water isotopologues follow the convection intensity. Besides, the spatial distribution of JJAS precipitation and OLR for the 2006-10 period well represents the climatology for the period 1979-2013 (Fig. 4; see also Fig. S2 in the supplemental material).

In general, surface evaporation flux is isotopically heavier than atmospheric water vapor (e.g., Moore et al. 2014). The weak convective regions, such as the western Indian Ocean and central Pacific, also receive less precipitation and serve as moisture sources to other regions (e.g., Castillo et al. 2014; van der Ent and Savenije 2013). Thus, the atmospheric water vapor is isotopically enriched as the dominate contribution of surface evaporation (Lee et al. 2007; Moore et al. 2014). Conversely, in the regions with strong convection or moisture convergence, converged water vapor has a larger contribution to the atmospheric water vapor, resulting in low water vapor isotope values. Besides, as precipitation always tend to remove heavy isotopes from water vapor (e.g., Dansgaard 1964), strong precipitation also contributes to low water vapor isotope values. In addition, rainfall reevaporation and rain-vapor exchange (e.g., Lawrence and Gedzelman 1996) in unsaturated downdrafts (e.g., Risi et al. 2008a) and mesoscale descents (e.g., Kurita 2013) associated with deep convection also isotopically deplete subcloud water vapor. As the subcloud water vapor will feed the condensation, these processes in turn exert indirect influence on the precipitation isotope composition (e.g., Risi et al. 2008a). Moreover, 
low condensation temperature at high altitude associated with deep convection directly leads to low precipitation isotope values (e.g., Cai and Tian 2016).

However, there are two locations where variations in water isotopologue compositions do not follow variations in convection. One is where the water isotopologue composition reaches its lowest value downstream of the peaks in convection (the lowest OLR values being around $90^{\circ} \mathrm{E}$ ) and upward air motion intensity (the lowest $\omega$ being around $95^{\circ} \mathrm{E}$ ) (Figs. 1 and 3 ). The other is where both precipitation and water vapor isotope values show a decreasing east-west trend roughly between $120^{\circ}$ and $150^{\circ} \mathrm{E}$, despite convection not having a longitudinal trend, and when upward air motion intensity even exhibits a decreasing east-west trend (Figs. 1 and 3).

In general, upstream atmospheric processes can also influence the isotopic compositions of water vapor and precipitation by affecting the converged water vapor isotope composition. To investigate the influence of the transport of nonlocal signals, we analyzed the vertical integral water vapor transport pattern (Fig. 5). A comparison between water isotopologue compositions (Figs. 1, 2a, and 3), convection (Fig. 3), and atmospheric water vapor transport patterns (Fig. 5) suggests that the mismatch between convection and water isotopologues in the two locations is caused by atmospheric water vapor transport. A weakening in convection will increase water isotopologue values, but the transport of isotopically depleted upstream water vapor may compensate, or even surpass, the influence of weakening in convection. Under such circumstances, the spatial patterns in TES $\delta \mathrm{D}_{v}$ and precipitation $\delta^{18} \mathrm{O}$ are governed by the effect of convection and, in part, atmospheric water vapor transport.

\section{b. Interannual variations of TES $\delta D_{v}$}

In previous section, we have pointed out the role of convection in controlling the spatial water vapor $\delta \mathrm{D}_{v}$ variability. Besides, early studies have suggested that temporal variations in isotopic composition of atmospheric water vapor and precipitation are linked to changes in convection intensity in tropical and monsoon regions (e.g., Cai and Tian 2016; He et al. 2015; Lee et al. 2015; Risi et al. 2008a). Thus, we investigated the changes in convection during the 2009 JJAS El Niño event and the 2010 JJAS La Niña event.

Figure 6 shows the JJAS precipitation and OLR anomalies (relative to the 2006-10 JJAS mean) during 2009 and 2010. During JJAS 2009, the maps illustrate overall positive OLR anomalies and negative precipitation anomalies over the R_W120 and both southern and northern parts of the R_WP. In contrast, negative OLR anomalies and positive precipitation anomalies

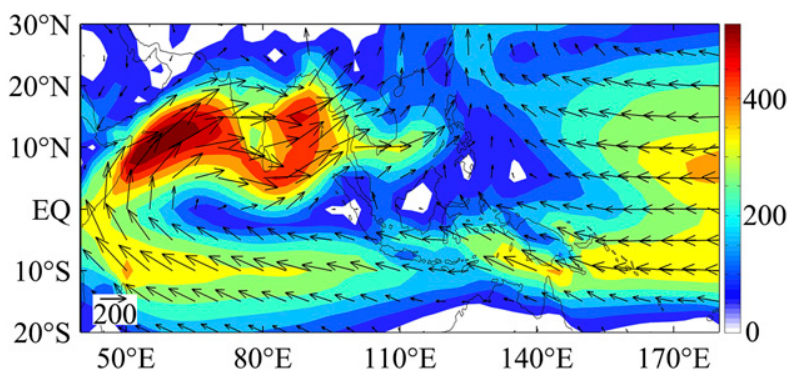

FIG. 5. JJAS seasonal vertical integral water vapor transport (plotted as vectors and shading, $\mathrm{kg} \mathrm{m}^{-1} \mathrm{~s}$ ) for the 2006-10 mean.

dominate the R_W120 and R_WP, except the central R_WP. These results suggest that convection and precipitation intensity over the R_W120 are weaker during the 2009 JJAS El Niño event and stronger during the 2010 JJAS La Niña event. Such changes in convection and precipitation are consistent with changes in $\delta \mathrm{D}_{v}$ in the R_W120 region (Figs. 2 and 6). Thus, the response of TES $\delta \mathrm{D}_{v}$ values over the R_W120 to ENSO seems like a result of direct response to deep convection. A previous study of the influence of OctoberDecember 2006 El Niño event on isotopic composition of water vapor over the Indian Ocean also suggest that the higher water vapor $\delta \mathrm{D}_{v}$ is associated with weaker and/or shallower convection (Lee et al. 2015).

\section{c. Understanding the unexpected response of TES $\delta D_{v}$ to convection in the $R_{-} W P$}

We have already outlined the negative $\delta \mathrm{D}_{v}$-ENSO response over the R_WP (Fig. 2). To understand this phenomenon, we focused specifically on longitudinal water vapor transport in the research region.

Generally, the isotopic composition of atmospheric water vapor in a column is controlled by fractionation during phase changes and the mixing of different water vapor fluxes. These water vapor fluxes mainly include evaporation flux from the land and sea surface and convergence flux from the immediate surroundings. The variation in the isotopic composition of sea surface evaporation flux is small over this region (Aggarwal et al. 2004), and the evaporation flux only accounts for a small contribution to the variation in the isotopic composition of atmospheric water vapor, compared with the contributions made by fractionation processes and the convergence flux (Yoshimura et al. 2003). In addition, the changes in evaporation flux over the R_WP during the 2009 JJAS period (2\% larger than the 2006-10 JJAS mean) and the 2010 JJAS period (identical to the 2006-10 JJAS mean) are small. It is therefore reasonable to believe that the evaporation flux is not the main cause of the interannual changes in TES $\delta \mathrm{D}_{v}$ values over the R_WP. 

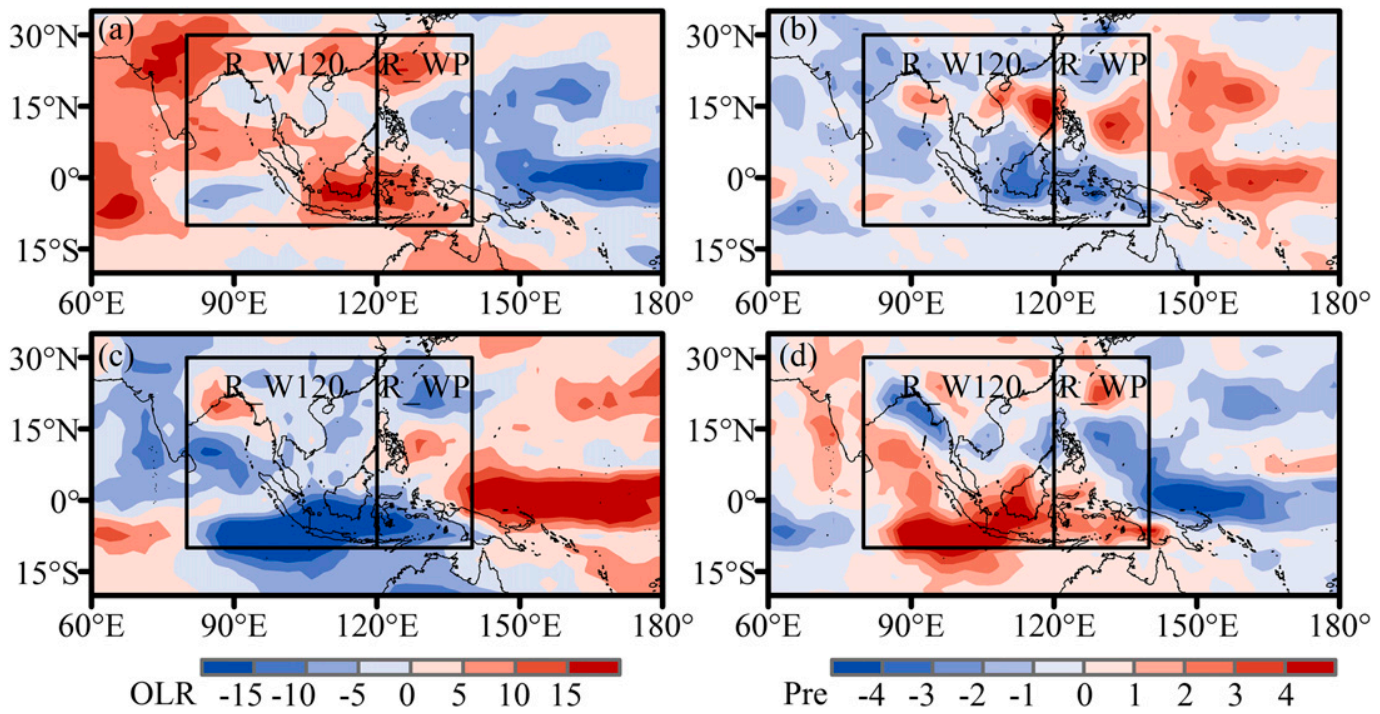

FIG. 6. JJAS (a) OLR $\left(\mathrm{W} \mathrm{m}^{-2}\right)$ and (b) precipitation $\left(\mathrm{mm} \mathrm{day}^{-1}\right)$ anomalies in 2009. (c),(d) As in (a),(b), but for anomalies in 2010. Anomalies are relative to the 2006-10 JJAS mean. Rectangles highlight the locations of R_W120 and R_WP.

In addition, fractionation processes during periods of stronger convection should decrease precipitation and water vapor isotope values (e.g., Cai and Tian 2016; He et al. 2015; Lee et al. 2015); such an effect should contribute to a positive isotope-ENSO response over both the northern and southern parts of the R_WP. As the transport of water vapor with different isotopic signatures can also alter the isotopic composition of water vapor, is it possible that the changes in atmospheric water vapor transport patterns led to the observed negative $\delta \mathrm{D}_{v}-$ ENSO response over the R_WP (Fig. $2 \mathrm{~b}$ )? To answer this question, we further analyzed the effect of moisture flux in association with interannual patterns in TES $\delta \mathrm{D}_{v}$.

We first compared the longitudinal variations in TES $\delta \mathrm{D}_{v}$, convection (OLR and $\omega$ ), and longitudinal water vapor transport anomalies (EFLUX; positive values indicate anomalous eastward water vapor transport, and anomalies are relative to the 2006-10 JJAS mean) in JJAS 2009 and JJAS 2010 (Fig. 7). Additionally, to quantify the changes in water vapor transport, we analyzed the spatial water vapor transport anomalies in JJAS 2009 and JJAS 2010 (Fig. 8), in addition to the water vapor fluxes across the R_W120 and R_WP boundary during the three periods (Table 1). Over the R_W120, the JJAS water vapor transport anomalies are relatively small between 2009 and 2010 (Fig. 8), and the weaker (stronger) convection in JJAS 2009 (2010) is responsible for the higher (lower) TES $\delta \mathrm{D}_{v}$ values (Fig. 7), in agreement with a previous study of the October-December 2006 El Niño event (Lee et al. 2015)
From Fig. 7 and Table 1, we can see similar changes in convection and water vapor convergence strength (somewhat represented by the atmospheric water budget) over the R_W120 and R_WP, but a difference in the changes in TES $\delta \mathrm{D}_{v}$. The different behavior of TES $\delta \mathrm{D}_{v}$ must therefore be less related to atmospheric convection over the R_WP than over the R_W120. Aside from convection, the change in magnitude in water vapor transport values is rather more evident for the R_WP (Figs. 7c and 8 and Table 1). The strength in westward water vapor transport rises dramatically (being 2.4 times larger than the 2006-10 JJAS mean, averaged over the R_WP) in JJAS 2010 but drops dramatically in JJAS 2009 [being -0.1 (changing into a net eastward transport) less than the 2006-10 JJAS mean, averaged over the R_WP].

During JJAS 2010, a drier period with less convection leads to an increase in TES $\delta \mathrm{D}_{v}$ values over the central Pacific (Figs. 6 and 7). The westward transport of such water vapor with elevated isotopic values gives a positive anomaly to TES $\delta \mathrm{D}_{v}$ values along the transport pathway. Additionally, the TES $\delta \mathrm{D}_{v}$ is higher over the central Pacific and lower over the western Pacific (Figs. 2a and 3). The dramatic increase in westward water vapor transport (Fig. 7d and Table 1) is likely to have carried more water vapor from the central Pacific to the western Pacific, thus also elevating TES $\delta \mathrm{D}_{v}$ values over the R_WP. As such, TES $\delta \mathrm{D}_{v}$ values over the R_WP are higher during JJAS 2010, despite convection being stronger.

During JJAS 2009, an anomalous westerly moisture flux transported water vapor from the R_W120 to the 


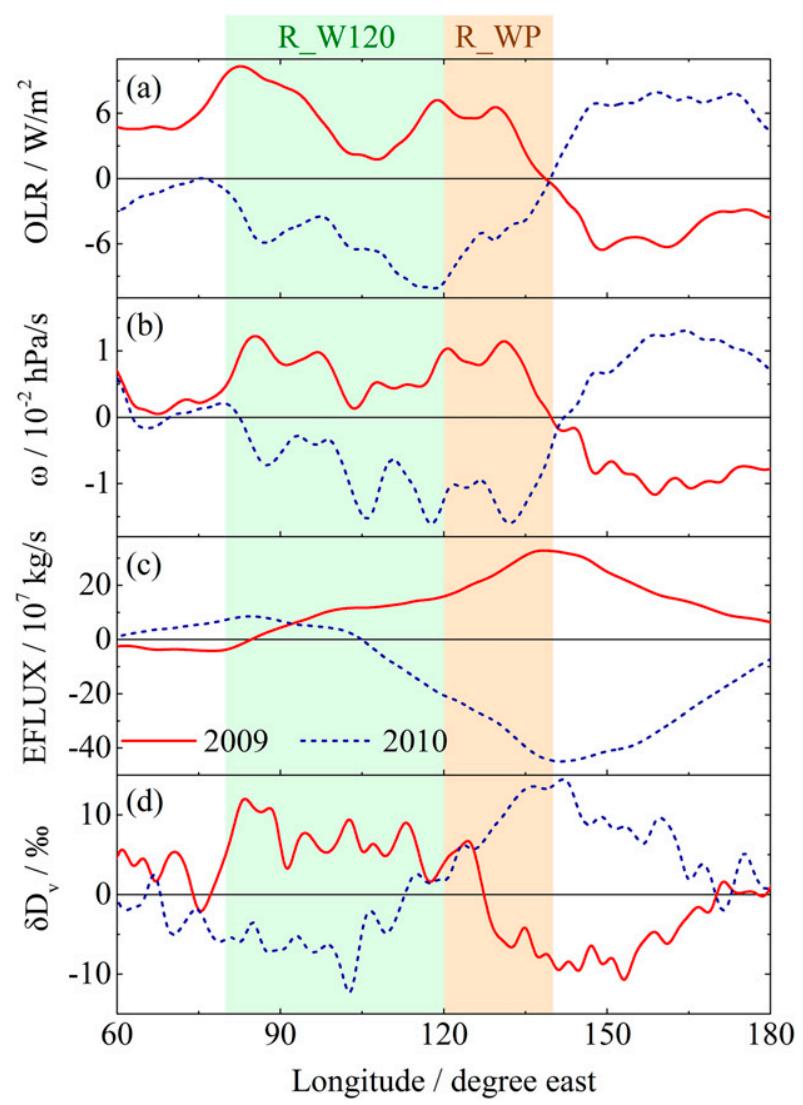

FIG. 7. Longitudinal variations in JJAS seasonal (a) OLR, (b) vertical velocity at $500 \mathrm{hPa}$, (c) vertical integral eastward moisture flux (EFLUX), and (d) water vapor $\delta \mathrm{D}_{v}$ anomalies (relative to the 2006-10 JJAS mean) for the latitude band $10^{\circ} \mathrm{S}-30^{\circ} \mathrm{N}$ in 2009 (solid red lines) and 2010 (dashed blue lines). The shadings denote the R_W120 (light green) and R_WP (light red) regions.

R_WP region (Fig. $8 \mathrm{~b}$ and Table 1 ). However, the longitudinal $\delta \mathrm{D}_{v}$ gradient around $120^{\circ} \mathrm{E}$ is small (Fig. 3). The influence of water vapor transport on temporal variations in water vapor-isotopic composition is determined by both transport intensity and the spatial water vapor-isotopic gradient [e.g., Eq. (5) in Okazaki et al. (2015)]. As such, water vapor transport across the western boundary of the R_WP is likely to have caused minimal influence on R_WP TES $\delta \mathrm{D}_{v}$ values during JJAS 2009, although the deviation in TES $\delta \mathrm{D}_{v}$ somewhat mirrors the deviation in convection over the western sector of the R_WP (Fig. 7). In the east, contrary to the La Niña event, less isotopically enriched water vapor was transported into the R_WP, and thus lower TES $\delta \mathrm{D}_{v}$ values occur over the eastern sector of the R_WP (Table 1 and Fig. 7).

To verify whether the water vapor transport and convection anomalies in these two events are typical El Niño or La Niña years, we analyzed the composites of precipitation, OLR, cloud-top pressure, and moisture

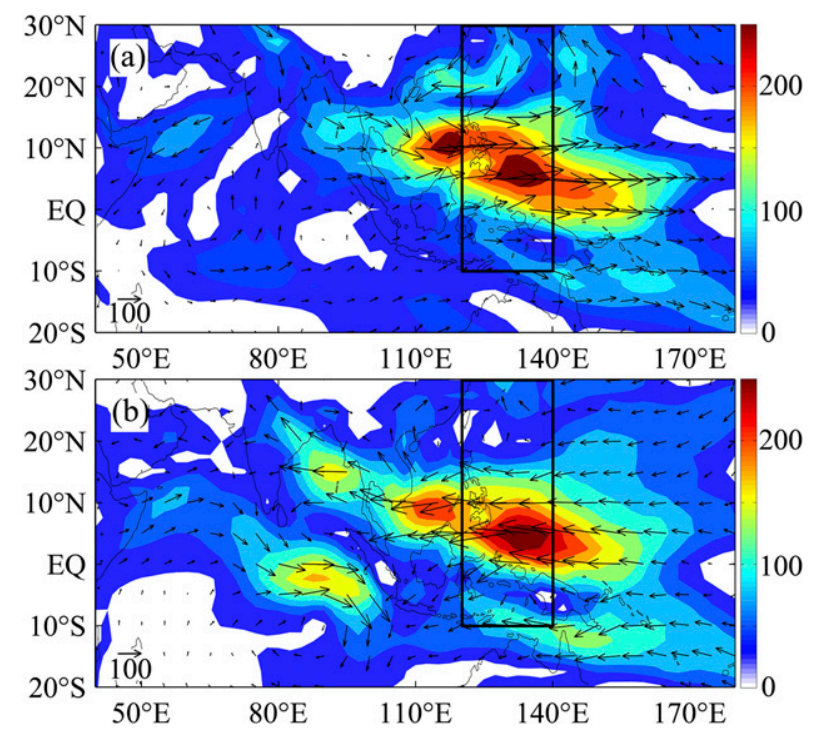

FIG. 8. JJAS seasonal vertical integral water vapor transport (plotted as vectors and shading, $\mathrm{kg} \mathrm{m}^{-1} \mathrm{~s}$ ) anomalies in (a) 2009 and (b) 2010. Anomalies are relative to the 2006-10 JJAS mean. Rectangles highlight the location of the R_WP.

flux anomalies based on ENSO metrics for about the last 30 years (Figs. S3 and S4 in the supplemental material). The results show that both convection and water vapor transport anomalies in JJAS 2009 and JJAS 2010 resemble the patterns in the averaged El Niño or La Niña conditions. The largest difference among these composites is the magnitudes in the JJAS 2009 and JJAS 2010 case are larger than the averaged conditions and the location of the largest moisture flux anomalies in the JJAS 2009 occurs about $10^{\circ}-20^{\circ}$ longitude west of that in the averaged El Niño condition. In summary, the conditions in the Indo-Pacific region in the specific case of JJAS 2009 and JJAS 2010 is representative of a typical El Niño and La Niña event, respectively.

\section{Discussion}

Aside from the altitude effect, precipitation $\delta^{18} \mathrm{O}$ and TES $\delta \mathrm{D}_{v}$ values show a similar spatial pattern: a Vshaped longitudinal variation. On the temporal scale, when ENSO varies, atmospheric water vapor isotopologues in the R_W120 and R_WP vary in opposition. TES $\delta \mathrm{D}_{v}$ shows a positive isotope-ENSO response in the R_W120 but a negative isotope-ENSO response in the R_WP.

To understand how the atmospheric circulation and, more specifically, convection and water vapor transport control the observed spatial and interannual patterns in Indo-Pacific water vapor isotopologues, we made a schematic diagram showing the relation between atmospheric water vapor $\delta \mathrm{D}_{v}$ and atmospheric circulation 
TABLE 1. Vertical integral of JJAS water vapor transport $\left(10^{6} \mathrm{~kg} \mathrm{~s}^{-1}\right.$; positive values indicate influx $)$ across the four boundaries of the two regions, R_W120 and the R_WP; the corresponding atmospheric water budget $\left(10^{6} \mathrm{~kg} \mathrm{~s}^{-1}\right)$, precipitation $P\left(10^{6} \mathrm{~kg} \mathrm{~s}{ }^{-1}\right)$, and OLR $\left(\mathrm{W} \mathrm{m}^{-2}\right)$ over the two regions for the 2006-10 JJAS mean; the 2009 and 2010 JJAS periods are also reported.

\begin{tabular}{|c|c|c|c|c|c|c|}
\hline & \multicolumn{3}{|c|}{ R_W120 } & \multicolumn{3}{|c|}{ R_WP } \\
\hline & 2006-10 mean & 2009 & 2010 & 2006-10 mean & 2009 & 2010 \\
\hline West & 600.9 & 676.1 & 653.4 & -31.9 & 185.0 & -308.8 \\
\hline East & 31.9 & -185.0 & 308.8 & 503.1 & 187.0 & 950.6 \\
\hline South & 241.8 & 283.1 & 143.6 & 100.3 & 87.6 & 101.2 \\
\hline North & -160.2 & -155.2 & -184.4 & -231.1 & -180.8 & -312.8 \\
\hline Budget & 714.5 & 619.0 & 921.4 & 340.4 & 278.8 & 430.2 \\
\hline$P$ & 1647.7 & 1504.0 & 1860.4 & 722.8 & 690.8 & 722.9 \\
\hline OLR & 220.0 & 224.5 & 212.9 & 230.6 & 233.7 & 227.4 \\
\hline
\end{tabular}

in the Indo-Pacific region (Fig. 9). Figure 9a describes how atmospheric circulation controls the longitudinal variations in precipitation and water vapor isotopes. In the moisture source regions (i.e., the western Indian Ocean and the central-eastern Pacific), convection is weaker and the cloud top is low, with higher cloud-top temperature (Fig. 9a); precipitation and water vapor are thus isotopically enriched. Along with the monsoonal and trade wind flows, precipitation $\delta^{18} \mathrm{O}$ and TES $\delta \mathrm{D}_{v}$ values gradually decrease with the progressive rainout and increase in convective intensity. The spatial patterns in JJAS precipitation $\delta^{18} \mathrm{O}$ are similar to the spatial patterns in annual precipitation $\delta^{18} \mathrm{O}$ (Aggarwal et al. 2004; Ishizaki et al. 2012). Aggarwal et al. (2004) suggested that the admixture of moisture from higher latitudes was an additional cause of the low precipitation isotopic values observed in the ocean monsoon trough (Chan and Evans 2002).

On the temporal scale, the significant suppression in convective intensity in the central part of the IndoPacific region during the El Niño event, but the relatively small changes in moisture flux over the R_W120, leads to positive anomalies in TES $\delta \mathrm{D}_{v}$ over the R_W120 (Fig. 9b). During the La Niña event, opposite anomalies prevail (Fig. 9c). Thus, the relationship between water vapor isotopologues over the R_W120 and ENSO can be attributed to the direct response of R_W120 water vapor isotopologues to deep convection.

Conversely, TES $\delta \mathrm{D}_{v}$ values over the R_WP in JJAS 2010 are higher than in JJAS 2009. We propose that this can be explained by changes in water vapor transport. Besides the studies in southeastern Asia (Cai and Tian 2016; Ichiyanagi and Yamanaka 2005; Ishizaki et al. 2012; Tan 2014), Conroy et al. (2013) found that western Pacific precipitation $\delta^{18} \mathrm{O}$ also has a positive correlation with ENSO, but they also pointed out that, in the equatorial central Pacific, westward water vapor transport displaces the precipitation $\delta^{18} \mathrm{O}$ anomaly west of the maximum rainfall anomaly. Thus, when ENSO varies, the precipitation $\delta^{18} \mathrm{O}$ in the R_WP varies in a way consistent with the amount effect, but the TES $\delta \mathrm{D}_{v}$ in the R_WP varies in a way that contradicts the expectation based on the amount effect. Convection activity impacts both water vapor and precipitation isotopic composition, but in different ways. In particular, the impact of rain evaporation (Risi et al. 2008a; Yoshimura et al. 2010) and of condensation altitude (Cai and Tian 2016; Permana et al. 2016) on the isotopic composition is different for precipitation than for water vapor. We therefore propose that convection is the primary control of precipitation isotopologues in the R_W120 and R_WP, but that changes in the relative proportions of water vapor from different source regions cannot fully explain variations in precipitation isotopologues (Nan et al. 2014; Tan 2014).

Additionally, this study shows the potential of using remote sensing water vapor isotopologues to study the influence of ENSO activity on the atmospheric water cycle. Although the influence of water vapor transport and convection on water vapor isotope composition has not been quantified in this study, our findings do imply that the observation of water vapor isotopologues can provide insight into isotopic processes in the water cycle. Sensitive experiments in modeling studies (e.g., Okazaki et al. 2015; Yoshimura et al. 2003) have attempted to quantify the relative contributions made by water vapor transport and fractionation processes toward influencing the isotopic composition of water vapor and precipitation.

\section{Conclusions}

This study investigated convection and water vapor transport controls on the spatial and interannual patterns evident in Indo-Pacific water vapor isotopologues. Both the isotopic compositions of precipitation and atmospheric water vapor show a V-shaped longitudinal variation, interpreted by the progressive rainout and increase in convective intensity along water vapor transport routes from both west and east to the central part of the Indo-Pacific region. On the temporal scale, 


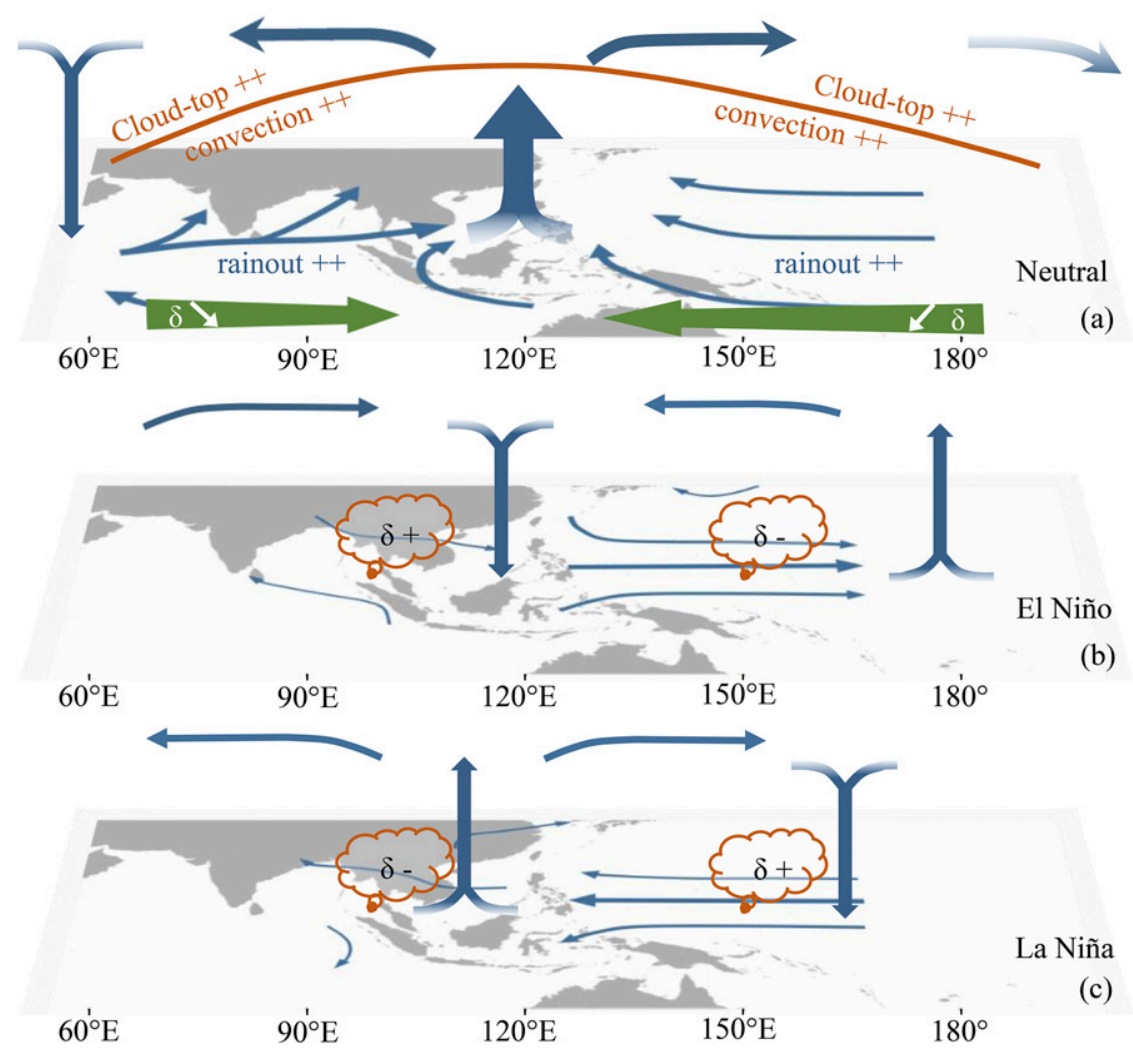

FIG. 9. Schematic diagram showing how atmospheric processes govern (a) the spatial patterns of Indo-Pacific water vapor isotopologues for a neutral-ENSO event and their responses to (b) El Niño and (c) La Niña events. Double plus signs indicate a gradual increase; a single plus sign indicates a positive anomaly and a minus sign indicates a negative anomaly. Blue arrows indicate water vapor transport pathways. Orange lines indicate the longitudinal distribution of cloud tops. Green arrows indicate longitudinal trends in water isotope composition in relation to water vapor transport and increased convection. Note that the conditions described in (b) and (c) are anomalies.

TES $\delta \mathrm{D}_{v}$ over the R_W120 is higher in the 2009 JJAS El Niño event and lower in the 2010 JJAS La Niña event, but TES $\delta \mathrm{D}_{v}$ over the R_WP varies in opposition.

We speculated on the cause for this inverse relation by comparing the variations in TES $\delta \mathrm{D}_{v}$, moisture transport, and OLR, and isolated the processes involved. The decrease of TES $\delta \mathrm{D}_{v}$ over the R_W120 as convection increases during La Niña, and vice versa during El Niño, appears to be caused by the expected response of water vapor isotopologues to convection, consistent with the amount effect. Subsiding air motion anomalies suppress convection over the R_W120 and lead to higher water vapor-isotopic values during El Niño events. During La Niña events, the opposite prevails and leads to lower water vapor-isotopic values. In contrast, the negative response of TES $\delta \mathrm{D}_{v}$ over the R_WP is caused mainly by changes in water vapor transport in this region.

Here we present a simple explanation of how convection and moisture transport produce the observed atmospheric water vapor $\delta \mathrm{D}_{v}$ over the R_WP in a typical La Niña year (2010) and its counterpart El Niño year (2009). During JJAS 2010 (2009) the La Niña (El Niño) event, the suppression (enhancement) of convection over the central Pacific elevates (lowers) $\delta \mathrm{D}_{v}$ values there. Westward water vapor transport pathways introduce positive (negative) anomalies to the R_WP. In addition, strengthened (weakened) trade winds transport more (less) isotopically enriched water vapor from the central Pacific to the western Pacific. Such changes in atmospheric water vapor transport elevate (lower) $\delta \mathrm{D}_{v}$ values over the R_WP. Although anomalous westerly winds transport water vapor west of $120^{\circ} \mathrm{E}$ to the western sector of the R_WP during JJAS 2009, such an anomalous water vapor transport event cannot mask the influence of the suppression of convection on $\delta \mathrm{D}_{v}$ values, as the longitudinal $\delta \mathrm{D}_{v}$ gradient around $120^{\circ} \mathrm{E}$ is small. These results suggest that convection and water vapor transport have competing roles in influencing $\delta \mathrm{D}_{v}$ 
values over the R_WP. We would suggest that future modeling studies might allow the quantification of the relative contributions of convection and water vapor transport to $\delta \mathrm{D}_{v}$ values in this region.

Acknowledgments. We thank Dr. John Chiang and three anonymous reviewers for their comments and suggestions. We also thank colleagues at the Tibetan observation stations for collecting and measuring precipitation samples. The IAEA (GNIP database) provided part of the precipitation isotope data. The NASA Jet Propulsion Laboratory provided the TES satellite data. The NOAA/OAR/ESRL PSD provided the GPCP and OLR data. The NOAA/CPC provided the ONI data. The NASA Goddard Institute for Space Studies provided the ISCCP D2 products. The ECMWF public datasets web interface provided the ERA-Interim and ERA-Interim/Land data. This research is supported by the National Natural Science Foundation of China (Grants 91437110 and 41530748), the "Strategic Priority Research Program (B)" of the Chinese Academy of Sciences (Grant XDB03030100), and CAS Hundred Talents Program.

\section{REFERENCES}

Adler, R. F., and Coauthors, 2003: The version-2 Global Precipitation Climatology Project (GPCP) Monthly Precipitation Analysis (1979-present). J. Hydrometeor., 4, 1147-1167, doi:10.1175/ 1525-7541(2003)004<1147:TVGPCP $>2.0$.CO;2.

Aggarwal, P. K., K. Fröhlich, K. M. Kulkarni, and L. L. Gourcy, 2004: Stable isotope evidence for moisture sources in the Asian summer monsoon under present and past climate regimes. Geophys. Res. Lett., 31, L08203, doi:10.1029/2004GL019911.

An, Z., and Coauthors, 2015: Global monsoon dynamics and climate change. Annu. Rev. Earth Planet. Sci., 43, 29-77, doi:10.1146/ annurev-earth-060313-054623.

Balsamo, G., and Coauthors, 2015: ERA-Interim/Land: A global land surface reanalysis data set. Hydrol. Earth Syst. Sci., 19, 389-407, doi:10.5194/hess-19-389-2015.

Cai, Z., and L. Tian, 2016: Atmospheric controls on seasonal and interannual variations in the precipitation isotope in the East Asian monsoon region. J. Climate, 29, 1339-1352, doi:10.1175/ JCLI-D-15-0363.1.

Castillo, R., R. Nieto, A. Drumond, and L. Gimeno, 2014: The role of the ENSO cycle in the modulation of moisture transport from major oceanic moisture sources. Water Resour. Res., 50 , 1046-1058, doi:10.1002/2013WR013900.

Chan, S. C., and J. L. Evans, 2002: Comparison of the structure of the ITCZ in the west Pacific during the boreal summers of 1989-93 using AMIP simulations and ECMWF reanalysis. J. Climate, 15, 3549-3568, doi:10.1175/1520-0442(2002)015<3549: COTSOT $>2.0 . \mathrm{CO} ; 2$.

Conroy, J. L., K. M. Cobb, and D. Noone, 2013: Comparison of precipitation isotope variability across the tropical Pacific in observations and SWING2 model simulations. J. Geophys. Res. Atmos., 118, 5867-5892, doi:10.1002/jgrd.50412.

Dansgaard, W., 1964: Stable isotopes in precipitation. Tellus, 16, 436-468, doi:10.1111/j.2153-3490.1964.tb00181.x.
Dee, D. P., and Coauthors, 2011: The ERA-Interim reanalysis: Configuration and performance of the data assimilation system. Quart. J. Roy. Meteor. Soc., 137, 553-597, doi:10.1002/ qj.828.

Ding, Y., and J. C. L. Chan, 2005: The East Asian summer monsoon: An overview. Meteor. Atmos. Phys., 89, 117-142, doi:10.1007/ s00703-005-0125-z.

Feng, X., A. M. Faiia, and E. S. Posmentier, 2009: Seasonality of isotopes in precipitation: A global perspective. J. Geophys. Res., 114, D08116, doi:10.1029/2008JD011279.

He, Y., and Coauthors, 2015: Impact of atmospheric convection on south Tibet summer precipitation isotopologue composition using a combination of in situ measurements, satellite data and atmospheric general circulation modeling. J. Geophys. Res. Atmos., 120, 3852-3871, doi:10.1002/2014JD022180.

Ichiyanagi, K., and M. D. Yamanaka, 2005: Interannual variation of stable isotopes in precipitation at Bangkok in response to $\mathrm{El}$ Niño Southern Oscillation. Hydrol. Processes, 19, 3413-3423, doi:10.1002/hyp.5978.

Ishizaki, Y., K. Yoshimura, S. Kanae, M. Kimoto, N. Kurita, and T. Oki, 2012: Interannual variability of $\mathrm{H}_{2}{ }^{18} \mathrm{O}$ in precipitation over the Asian monsoon region. J. Geophys. Res., 117, D16308, doi:10.1029/2011JD015890.

Ju, J., and J. Slingo, 1995: The Asian summer monsoon and ENSO. Quart. J. Roy. Meteor. Soc., 121, 1133-1168, doi:10.1002/ qj.49712152509.

Krishnamurthy, L., and V. Krishnamurthy, 2014: Influence of PDO on South Asian summer monsoon and monsoonENSO relation. Climate Dyn., 42, 2397-2410, doi:10.1007/ s00382-013-1856-z.

Krishnamurti, T. N., L. Stefanova, and V. Misra, 2013: El Niño and Southern Oscillation. Tropical Meteorology, T. N. Krishnamurti, L. Stefanova, and V. Misra, Eds., Springer, 197-220.

Kurita, N., 2013: Water isotopic variability in response to mesoscale convective system over the tropical ocean. J. Geophys. Res. Atmos., 118, 10376-10390, doi:10.1002/jgrd.50754.

Lawrence, R. J., and D. S. Gedzelman, 1996: Low stable isotope ratios of tropical cyclone rains. Geophys. Res. Lett., 23, 527530, doi:10.1029/96GL00425.

Lee, J., and Coauthors, 2011: Relating tropical ocean clouds to moist processes using water vapor isotope measurements. Atmos. Chem. Phys., 11, 741-752, doi:10.5194/acp-11-741-2011.

, J. Worden, D. Noone, J. H. Chae, and C. Frankenberg, 2015: Isotopic changes due to convective moistening of the lower troposphere associated with variations in the ENSO and IOD from 2005 to 2006. Tellus, 67B, 26177, doi:10.3402/tellusb. v67.26177.

Lee, J.-E., and I. Fung, 2008: "Amount effect" of water isotopes and quantitative analysis of post-condensation processes. Hydrol. Processes, 22, 1-8, doi:10.1002/hyp.6637.

,-- D. J. DePaolo, and C. C. Henning, 2007: Analysis of the global distribution of water isotopes using the NCAR atmospheric general circulation model. J. Geophys. Res., 112, D16306, doi:10.1029/2006JD007657.

, C. Risi, I. Fung, J. Worden, R. A. Scheepmaker, B. Lintner, and C. Frankenberg, 2012: Asian monsoon hydrometeorology from TES and SCIAMACHY water vapor isotope measurements and LMDZ simulations: Implications for speleothem climate record interpretation. J. Geophys. Res., 117, D15112, doi:10.1029/2011JD017133.

Liebmann, B., and C. A. Smith, 1996: Description of a complete (interpolated) outgoing longwave radiation dataset. Bull. Amer. Meteor. Soc., 77, 1275-1277. 
Moore, M., Z. Kuang, and P. N. Blossey, 2014: A moisture budget perspective of the amount effect. Geophys. Res. Lett., 41, 1329-1335, doi:10.1002/2013GL058302.

Nan, S., M. Tan, and P. Zhao, 2014: Evaluation of the ability of the Chinese stalagmite $\delta^{18} \mathrm{O}$ to record the variation in atmospheric circulation during the second half of the 20th century. Climate Past, 10, 975-985, doi:10.5194/cp-10-975-2014.

Noone, D., 2012: Pairing measurements of the water vapor isotope ratio with humidity to deduce atmospheric moistening and dehydration in the tropical midtroposphere. J. Climate, 25, 4476-4494, doi:10.1175/JCLI-D-11-00582.1.

Okazaki, A., Y. Satoh, G. Tremoy, F. Vimeux, R. Scheepmaker, and K. Yoshimura, 2015: Interannual variability of isotopic composition in water vapor over western Africa and its relationship to ENSO. Atmos. Chem. Phys., 15, 3193-3204, doi:10.5194/acp-15-3193-2015.

Permana, D. S., L. G. Thompson, and G. Setyadi, 2016: Tropical west Pacific moisture dynamics and climate controls on rainfall isotopic ratios in southern Papua, Indonesia. J. Geophys. Res. Atmos., 121, 2222-2245, doi:10.1002/2015JD023893.

Risi, C., S. Bony, and F. Vimeux, 2008a: Influence of convective processes on the isotopic composition $\left(\delta^{18} \mathrm{O}\right.$ and $\left.\delta \mathrm{D}\right)$ of precipitation and water vapor in the tropics: 2 . Physical interpretation of the amount effect. J. Geophys. Res., 113, D19306, doi:10.1029/2008JD009943.

- — - - L. Descroix, B. Ibrahim, E. Lebreton, I. Mamadou, and B. Sultan, 2008b: What controls the isotopic composition of the African monsoon precipitation? Insights from event-based precipitation collected during the 2006 AMMA field campaign. Geophys. Res. Lett., 35, L24808, doi:10.1029/2008GL035920.

, and Coauthors, 2012: Process-evaluation of tropospheric humidity simulated by general circulation models using water vapor isotopologues: 1. Comparison between models and observations. J. Geophys. Res., 117, D05303, doi:10.1029/ 2011JD016621.

Rossow, W. B., and R. A. Schiffer, 1999: Advances in understanding clouds from ISCCP. Bull. Amer. Meteor. Soc., 80, 2261-2287, doi:10.1175/1520-0477(1999)080<2261:AIUCFI >2.0.CO;2.

Scholl, M. A., J. B. Shanley, J. P. Zegarra, and T. B. Coplen, 2009: The stable isotope amount effect: New insights from NEXRAD echo tops, Luquillo Mountains, Puerto Rico. Water Resour. Res., 45, W12407, doi:10.1029/2008WR007515.

Sengupta, S., and A. Sarkar, 2006: Stable isotope evidence of dual (Arabian Sea and Bay of Bengal) vapour sources in monsoonal precipitation over north India. Earth Planet. Sci. Lett., 250, 511-521, doi:10.1016/j.epsl.2006.08.011.

Srivastava, R., R. Ramesh, N. Gandhi, R. A. Jani, and A. K. Singh, 2015: Monsoon onset signal in the stable oxygen and hydrogen isotope ratios of monsoon vapor. Atmos. Environ., 108, 117-124, doi:10.1016/j.atmosenv.2015.02.062.

Sutanto, S. J., G. Hoffmann, J. Worden, R. A. Scheepmaker, I. Aben, and T. Röckmann, 2015: Atmospheric processes governing the changes in water isotopologues during ENSO events from model and satellite measurements. J. Geophys. Res. Atmos., 120, 6712-6729, doi:10.1002/2015JD023228.
Tan, M., 2014: Circulation effect: Response of precipitation $\delta^{18} \mathrm{O}$ to the ENSO cycle in monsoon regions of China. Climate Dyn., 42, 1067-1077, doi:10.1007/s00382-013-1732-x.

Thompson, L. G., T. Yao, E. Mosley-Thompson, M. E. Davis, K. A. Henderson, and P.-N. Lin, 2000: A high-resolution millennial record of the South Asian monsoon from Himalayan ice cores. Science, 289, 1916-1919, doi:10.1126/science.289.5486.1916.

Tian, L., V. Masson-Delmotte, M. Stievenard, T. Yao, and J. Jouzel, 2001: Tibetan Plateau summer monsoon northward extent revealed by measurements of water stable isotopes. J. Geophys. Res., 106, 28 081-28 088, doi:10.1029/2001JD900186.

_ - T. Yao, K. MacClune, J. W. C. White, A. Schilla, B. Vaughn, R. Vachon, and K. Ichiyanagi, 2007: Stable isotopic variations in west China: A consideration of moisture sources. J. Geophys. Res., 112, D10112, doi:10.1029/2006JD007718.

Trenberth, K. E., 1997: The definition of El Niño. Bull. Amer. Meteor. Soc., 78, 2771-2777, doi:10.1175/1520-0477(1997)078<2771: TDOENO $>2.0 . \mathrm{CO} ; 2$.

van der Ent, R. J., and H. H. G. Savenije, 2013: Oceanic sources of continental precipitation and the correlation with sea surface temperature. Water Resour. Res., 49, 3993-4004, doi:10.1002/ wrcr.20296.

Wang, B., and LinHo, 2002: Rainy season of the Asian-Pacific summer monsoon. J. Climate, 15, 386-398, doi:10.1175/ 1520-0442(2002)015<0386:RSOTAP $>2.0 . C O ; 2$.

Worden, J., and Coauthors, 2006: Tropospheric emission spectrometer observations of the tropospheric $\mathrm{HDO} / \mathrm{H}_{2} \mathrm{O}$ ratio: Estimation approach and characterization. J. Geophys. Res., 111, D16309, doi:10.1029/2005JD006606.

- and Coauthors, 2011: Estimate of bias in Aura TES HDO/ $\mathrm{H}_{2} \mathrm{O}$ profiles from comparison of TES and in situ $\mathrm{HDO} / \mathrm{H}_{2} \mathrm{O}$ measurements at the Mauna Loa observatory. Atmos. Chem. Phys., 11, 4491-4503, doi:10.5194/acp-11-4491-2011.

- and Coauthors, 2012: Profiles of $\mathrm{CH}_{4}, \mathrm{HDO}, \mathrm{H}_{2} \mathrm{O}$, and $\mathrm{N}_{2} \mathrm{O}$ with improved lower tropospheric vertical resolution from Aura TES radiances. Atmos. Meas. Tech., 5, 397-411, doi:10.5194/ amt-5-397-2012.

Yang, X., T. Yao, W. Yang, B. Xu, Y. He, and D. Qu, 2012: Isotopic signal of earlier summer monsoon onset in the Bay of Bengal. J. Climate, 25, 2509-2516, doi:10.1175/JCLI-D-11-00180.1.

Yao, T., and Coauthors, 2013: A review of climatic controls on $\delta^{18} \mathrm{O}$ in precipitation over the Tibetan Plateau: Observations and simulations. Rev. Geophys., 51, 525-548, doi:10.1002/ $\operatorname{rog} .20023$.

Yoshimura, K., T. Oki, N. Ohte, and S. Kanae, 2003: A quantitative analysis of short-term ${ }^{18} \mathrm{O}$ variability with a Rayleigh-type isotope circulation model. J. Geophys. Res., 108, 4647, doi:10.1029/ 2003JD003477.

_- M. Kanamitsu, and M. Dettinger, 2010: Regional downscaling for stable water isotopes: A case study of an atmospheric river event. J. Geophys. Res., 115, D18114, doi:10.1029/2010JD014032.

Yu, W., and Coauthors, 2016: Short-term variability in the dates of the Indian monsoon onset and retreat on the southern and northern slopes of the central Himalayas as determined by precipitation stable isotopes. Climate Dyn., 47, 159-172, doi:10.1007/s00382-015-2829-1. 